\title{
Low Vision Clinical Services Need to Integrate with Social Rehabilitation
}

\section{Nahid Ferdausi*}

Associate Professor, Head of Low Vision Department, National Institute of Ophthalmology and Hospital, Dhaka, Bangladesh

*Corresponding Author: Nahid Ferdausi, Associate Professor, Head of Low Vision Department, National Institute of Ophthalmology and Hospital, Dhaka, Bangladesh.
Received: September 28, 2021

Published: November 09, 2021

(C) All rights are reserved by Nahid Ferdausi.
Persons with low-vision live in a gray area between typical correctable/normal vision and complete blindness. As opposed to blindness, low-vision is the state where one's eyesight is not completely lost but has significantly reduced.

Low-vision cannot be corrected or improved with glasses, contact lenses, or surgery.

Low-vision affects a person's quality of life in many ways, involving visual, functional, psychological, social, and economic factors. One does not have to give up the daily activities for low vision; rather acquiring and applying new ways of doing them would help to cope up with the difficulties. There are a wide range of tools, techniques, and resources for people with low vision. People with low vision need to learn to become independent to perform dayto-day activities.

Vision rehabilitation process consists of learning ways to optimize utilizing residual vision, using low-vision aids such as magnifiers and computer equipment, and adapting to the environment to compensate for low vision. In a developing country like Bangladesh, low-vision does not get much traction and remains a neglected issue.

In most cases, low vision patients are not aware that their vision will not improve.

Challenges for low vision exist both from the supply side and demand side.
Supply-side challenges are lack of specific evidence-based data and funding, lack of interest in low-vision services among the eye care professionals, specifically ophthalmologists, limited low vision service facilities, lack of availability of appropriate equipment/devices, expensive low vision assistive devices, shortage of human resources, poor multidisciplinary and multi-professional interaction, lack of standard operational guideline.

There are several demand-side challenges, such as lack of awareness and knowledge, barriers to social acceptance, social stigma and perception, negative attitudes, lack of proper information and availability of low vision devices, not being ready to use the low-vision devices.

Low vision services are not bound to reduce the visual deficits of low-vision patients but preferably serve them to function better with their vision limitations. Low-vision services aim to assist people in adapting to vision loss and still not be dependent on others. Also, it refers to help using as much of a person's remaining sight as possible and training on Low Vision Devices usage.

Low vision services do not concern only clinical assessment and treatment but also need rehabilitative services or social rehabilitation. These services help them to become educated, gain life skill training, and be employed.

The development and implementation of the 'National Low Vision Management Guideline' is an essential part of the proper establishment of low vision services and should aim for integration through coordination with eye health care providers, patients, so- 
cial workers, and non-government organizations. Operational research should be promoted to assess the effectiveness of services and quality of life of Low-Vision patients.

The potential benefits will be achieved under the public-private partnership model with all stakeholders working on clinical and rehabilitation services for people with low vision.

Volume 4 Issue 12 December 2021

(C) All rights are reserved by Nahid Ferdausi. 